\title{
Article \\ Phosphodiesterases Expression during Murine Cardiac Development
}

\author{
Thays Maria da Conceição Silva Carvalho ${ }^{1,+}{ }^{+}$Silvia Cardarelli ${ }^{1, \dagger}{ }^{+}$, Mauro Giorgi ${ }^{2}$, Andrea Lenzi ${ }^{3}$, \\ Andrea M. Isidori ${ }^{3}$ and Fabio Naro ${ }^{1, *(D)}$ \\ 1 Department of Anatomical, Histological, Forensic and Orthopedic Sciences, Sapienza University, \\ 00161 Rome, Italy; thaysmariadaconceiao.silvacarvalho@uniroma1.it (T.M.d.C.S.C.); \\ silvia.cardarelli@uniroma1.it (S.C.) \\ 2 Department of Biology and Biotechnology “C. Darwin”, Sapienza University, 00185 Rome, Italy; \\ mauro.giorgi@uniroma1.it \\ 3 Department of Experimental Medicine, Sapienza University, 00161 Rome, Italy; \\ andrea.lenzi@uniroma1.it (A.L.); andrea.isidori@uniroma1.it (A.M.I.) \\ * Correspondence: fabio.naro@uniroma1.it \\ + These authors contributed equally to this work.
}

check for updates

Citation: Carvalho, T.M.d.C.S.; Cardarelli, S.; Giorgi, M.; Lenzi, A.; Isidori, A.M.; Naro, F. Phosphodiesterases Expression during Murine Cardiac Development. Int. J. Mol. Sci. 2021, 22, 2593. http:// doi.org/10.3390/ijms22052593

Academic Editor: Saša Frank

Received: 24 January 2021

Accepted: 26 February 2021

Published: 5 March 2021

Publisher's Note: MDPI stays neutral with regard to jurisdictional claims in published maps and institutional affiliations.

Copyright: (c) 2021 by the authors. Licensee MDPI, Basel, Switzerland. This article is an open access article distributed under the terms and conditions of the Creative Commons Attribution (CC BY) license (https:// creativecommons.org/licenses/by/ $4.0 /)$.

\begin{abstract}
PDEs) are a large family of enzymes playing a fundamental role in the control of intracellular levels of cAMP and cGMP. Emerging evidence suggested an important role of phosphodiesterases in heart formation, but little is known about the expression of phosphodiesterases during cardiac development. In the present study, the pattern of expression and enzymatic activity of phosphodiesterases was investigated at different stages of heart formation. C57BL/ 6 mice were mated and embryos were collected from 14.5 to 18.5 days of development. Data obtained by qRT-PCR and Western blot analysis showed that seven different isoforms are expressed during heart development, and PDE1C, PDE2A, PDE4D, PDE5A and PDE8A are modulated from E14.5 to E18.5. In heart homogenates, the total cAMP and cGMP hydrolytic activity is constant at the evaluated times, and PDE4 accounts for the majority of the cAMP hydrolyzing ability and PDE2A accounts for cGMP hydrolysis. This study showed that a subset of PDEs is expressed in developing mice heart and some of them are modulated to maintain constant nucleotide phosphodiesterase activity in embryonic and fetal heart.
\end{abstract}

Keywords: cyclic nucleotides; heart development; phosphodiesterases

\section{Introduction}

Heart development is a complex process which requires an interplay of different transcription factors, signaling pathways and morphological modifications [1]. Mouse heart formation begins at embryonic day 7.5 (E7.5) when a group of mesodermal cells migrates to the midline, forming the cardiac crescent [1]. At E8.5, the cardiac crescent changes its conformation, forming the linear heart tube, cardiac looping occurs at E10.5, atrioventricular septation and trabeculation occurs at E12.5 and a four-chambered heart is formed at E14.5 [1]. At E15.5 and E16.5, the atrioventricular valve leaflets and the coronary arteries are modified, achieving the definitive conformation, and at E18.5, the definitive external prenatal heart configuration is completed [2].

The formation of the heart is tightly controlled by a set of signal transduction pathways including the intracellular second messenger cyclic adenosine monophosphate (cAMP) and cyclic guanosine monophosphate (cGMP) [3]. The intracellular levels of cyclic nucleotides are regulated by the balance between their synthesis and degradation. cAMP is synthesized by adenylyl cyclases through agonist binding to G-protein-coupled receptors. cGMP is produced by a soluble guanylyl cyclase activated by nitric oxide and a particulate guanylyl cyclase activated by the natriuretic peptides [4]. Both cyclic nucleotides are hydrolyzed by 
the $3^{\prime} 5^{\prime}$ cyclic nucleotides phosphodiesterases (PDEs) into their inactive forms $5^{\prime}$-AMP and 5'-GMP.

Eleven PDEs have been described and they are defined by their cellular functions, catalytic properties, protein structure and affinity for cAMP and cGMP [5]. Seven PDEs are expressed in the adult heart: PDE1, PDE2 and PDE3 which hydrolyze both cAMP and cGMP; PDE4 and PDE8 which hydrolyze cAMP; and PDE5 and PDE9 which are cGMP specific [6]. Despite the important role of the cAMP-cGMP/PDEs pathway in cardiac processes like contraction/relaxation, cell differentiation, proliferation and survival [7], very few data are available regarding PDEs' function in cardiac development. Recently, it was reported that there are seven PDE mRNAs expressed in the murine heart at different stages of development [8] and, more importantly, it was demonstrated that PDE2A plays a critical role in heart development because its genetic ablation induces congenital defects [9]. Table 1 reports current data, obtained in transgenic animal model, on PDE isoforms involved in cardiac functions.

Table 1. Overview of PDE isoforms involved in cardiac functions.

\begin{tabular}{|c|c|c|c|}
\hline $\begin{array}{l}\text { Phosphodiesterase } \\
\text { (PDE) Family }\end{array}$ & Gene & $\begin{array}{l}\text { Substrate/ } \\
\text { Regulation }\end{array}$ & Transgenic Model \\
\hline PDE1 & $1 \mathrm{~A}, 1 \mathrm{~B}, 1 \mathrm{C}$ & $\begin{array}{l}\text { cAMP/cGMP } \\
\mathrm{Ca}^{2+/} \mathrm{CaM} \\
\text { stimulated }\end{array}$ & $\begin{array}{c}\text { Pde1a knockout: } \\
\text { lowest blood pressure, increased heart } \\
\text { rate, elevated ejection fraction [10]. } \\
\text { Pde1c knockout: } \\
\text { protected from TAC-induced cardiac } \\
\text { dysfunction; antagonize cardiac } \\
\text { myocyte hypertrophy and death [11]. }\end{array}$ \\
\hline PDE2 & $2 \mathrm{~A}$ & $\begin{array}{l}\text { cAMP/cGMP } \\
\text { cGMP- } \\
\text { stimulated }\end{array}$ & $\begin{array}{c}\text { Pde2a knockout: } \\
\text { embryonal death, congenital heart } \\
\text { defect [9]. }\end{array}$ \\
\hline PDE3 & $3 \mathrm{~A}, 3 \mathrm{~B}$ & $\begin{array}{l}\text { cAMP / cGMP } \\
\text { cGMP- } \\
\text { inhibited }\end{array}$ & $\begin{array}{c}\text { Pde3a overexpression: } \\
\text { decreased heart rate and cardiac } \\
\text { contractile function; } \\
\text { antiapoptotic effect in adult } \\
\text { cardiomyocytes [12]. }\end{array}$ \\
\hline PDE4 & $\begin{array}{c}4 \mathrm{~A}, 4 \mathrm{~B}, 4 \mathrm{C} \\
4 \mathrm{D}\end{array}$ & cAMP & $\begin{array}{l}\text { Pde } 4 a \text { knockout: } \\
\text { no cardiac alteration [13]; } \\
\text { Pde } 4 d \text { knockout: } \\
\text { age-related cardiomyopathy; } \\
\text { arrhythmia [14]. }\end{array}$ \\
\hline PDE5 & $5 \mathrm{~A}$ & cGMP & $\begin{array}{l}\quad \text { Pde5a overexpression: } \\
\text { adverse cardiac remodeling after } \\
\text { myocardial infarction; enhanced } \\
\text { hypertrophy, reduced contractile } \\
\text { function [15]. }\end{array}$ \\
\hline PDE8 & $8 \mathrm{~A}, 8 \mathrm{~B}$ & cAMP & $\begin{array}{c}\text { Pde8a knockout: } \\
\text { increased } \mathrm{Ca}^{2+} \text { transient and current } \\
\text { during } \beta \text { AR stimulation [16]. }\end{array}$ \\
\hline PDE9 & $9 \mathrm{~A}$ & $\begin{array}{c}\text { cGMP } \\
\text { high affinity }\end{array}$ & $\begin{array}{c}\text { Pde9a knockout: } \\
\text { cardio-protected after sustained } \\
\text { pressure overload [17]. }\end{array}$ \\
\hline
\end{tabular}

Considering these observations, the present study was carried out to further characterize the pattern of PDE expression in cardiac development at mRNA, protein and activity levels. This information will provide a useful tool to clarify the role of PDEs in the framework of the cardiac development and their potential role in cardiac diseases. 


\section{Results}

2.1. PDE mRNA Expression Levels Vary between Embryonic and Fetal Cardiac Development

It was previously shown by semiquantitative reverse transcriptase polymerase chain reaction (RT-PCR) that the mRNAs of Pde1, Pde2, Pde3, Pde4, Pde5, Pde8 and Pde9 were present in the heart of embryonic and fetal mice [8]. In order to detect PDE expression changes in the developing heart, the mRNA levels of selected variants of these PDEs were measured by qRT-PCR at E14.5, E16.5 and E18.5 (Figure 1).
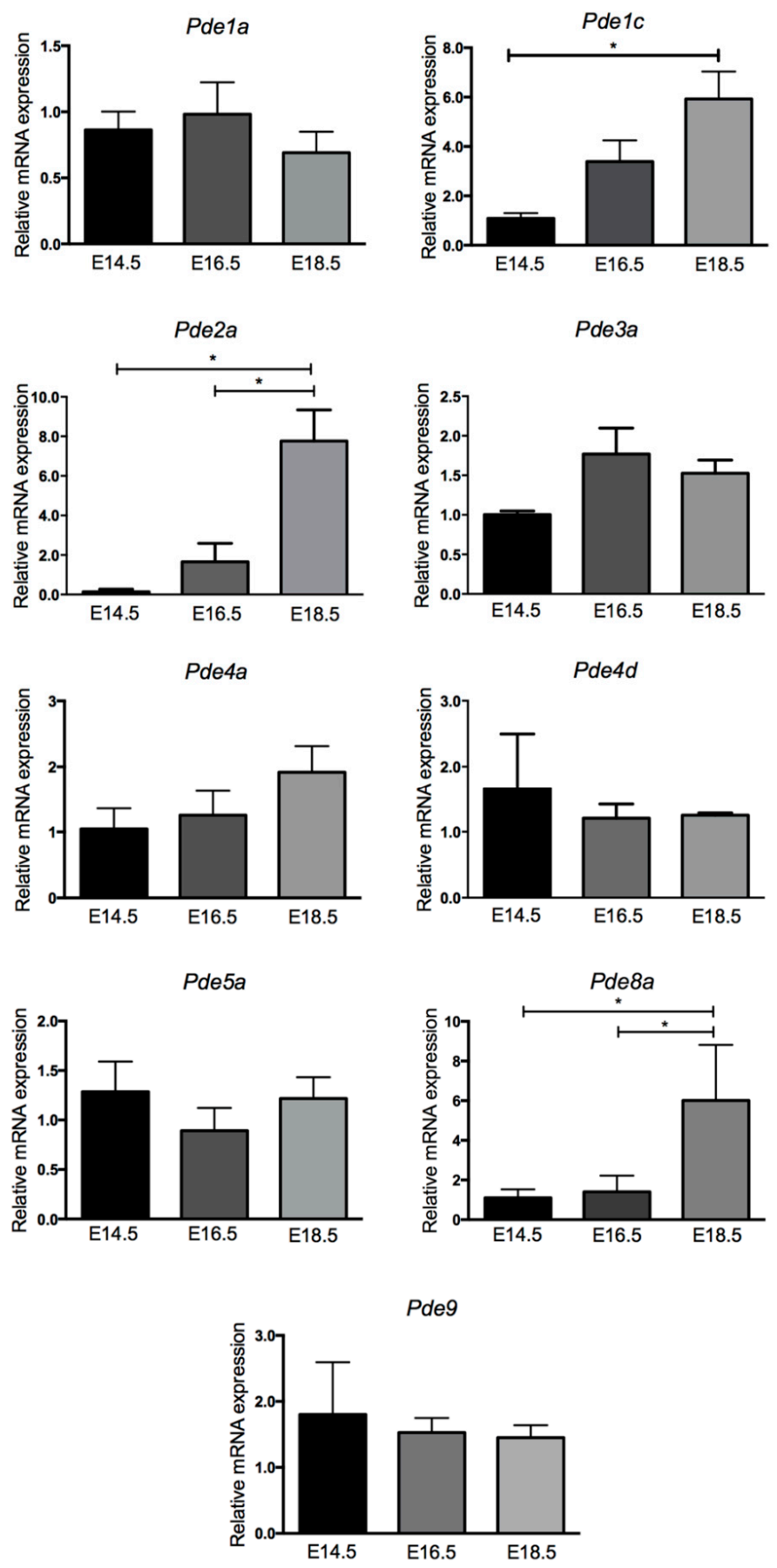

Figure 1. PDE gene expression during heart formation. qRT-PCR analysis of Pde1a, Pde1c, Pde2a, Pde3a, Pde4a, Pde4d, Pde5a, Pde8a and Pde9 mRNA expression in E14.5, E16.5 and E18.5 mouse hearts. The relative expression was normalized versus Gapdh gene. Data represent the mean $\pm \mathrm{SD}$ of five hearts for each stage. One-way ANOVA was used for statistical analysis. ${ }^{*} p<0.05$. 
The Pde1 gene encodes for three $(1 a, 1 b$ and $1 c) \mathrm{Ca}^{2+} /$ calmodulin (CaM)-stimulated phosphodiesterase activities, all able to hydrolyze both cAMP and cGMP [18]. Quantitative expression analysis showed that mRNA of Pde1a is present at similar levels at all stages of heart development. In contrast, Pde1c mRNA was expressed at very low levels at E14.5 and greatly increased expression at E16.5, reaching statistical significance at E18.5.

PDE2A is a cAMP and cGMP hydrolyzing activity stimulated by cGMP. Pde2a transcript, required for normal heart development [9], is expressed at low levels at E14.5 and showed a gradual increase over time with expression being significantly greater at E18.5.

PDE3A, comprising the 3A and 3B isoforms [12], is a member of the CGMP-inhibited phosphodiesterase, hydrolyzing both cAMP and cGMP.

Pde3a mRNA was moderately expressed at E14.5, increased at E16.5 and its levels were stabilized at the E18.5 stage.

PDE4 is a large family of enzymes (4A, 4B, 4C and 4D) encoded by four genes of which $4 a, 4 b$ and $4 d$ are expressed in the developing mouse heart and in cardiomyocytes $[8,19]$. Two mRNA of PDE4 isoforms expressed in the heart were analyzed, Pde4a and Pde4d. Both transcripts with little differences were expressed at comparable levels during all stages.

PDE5A, a cGMP-specific activity, has a major role as regulator of vascular smooth muscle contraction $[15,20]$. Pde5a mRNA maintained a profile of expression similar along all stages.

PDE8 is a cAMP specific activity comprising the $8 \mathrm{~A}$ and $8 \mathrm{~B}$ isoforms [16]. Pde8a mRNA was present at low levels between E14.5 and E16.5 and displayed, similar to Pde2a, a great increase from E16.5 to E18.5.

PDE9 isoforms specifically hydrolyze cGMP with the highest affinity among all PDE families, and they are expressed in cognitive-relevant regions of the brain $[17,21]$. Pde9 mRNA showed a constant level at all stages of heart formation.

Taken together, the mRNA expression of PDE isoforms can be grouped into mRNAs that are present at approximately the same level at any stage of heart development (Pde1a, Pde3a, Pde $4 a$ and Pde5a), mRNAs that tend to decrease with time (Pde4d and Pde9) and transcripts that are clearly upregulated with time (Pde1c, Pde2a and Pde8a).

\subsection{Variation of PDE Expression Occurs at Protein Levels in Embryonic and Fetal Heart}

Since no data are available regarding the translation of mRNA of PDE isoforms in the prenatal heart, Western blot (WB) analyses were performed to assess the presence of PDE isoform immunoreactivity on the same days in which mRNA expression was evaluated.

The WB analysis reported in Figure 2 showed a protein pattern profile that, with the exception of PDE4D and PDE5A, resembled the gene expression profile of Figure 1.

Briefly, PDE1A showed protein levels very similar at all stages of heart formation. Although PDE2A was almost undetectable at E14.5, PDE1C and PDE2A displayed an almost identical progressively increasing profile with the highest protein amounts at E18.5. PDE3A and PDE4A displayed protein amounts similar at all stages evaluated. The level of PDE4D was not modified between E14.5 and E16.5 but showed a significantly detected reduction at E18.5. The level of PDE5A protein greatly decreased from E14.5 to E16.5, reaching its lowest level at E18.5. PDE8A protein amount mirrors the same pattern of PDE2A with a progressive and significant increase during the stages of heart formation. The PDE9 protein was below the limit of quantification of employed methods (data not shown). 


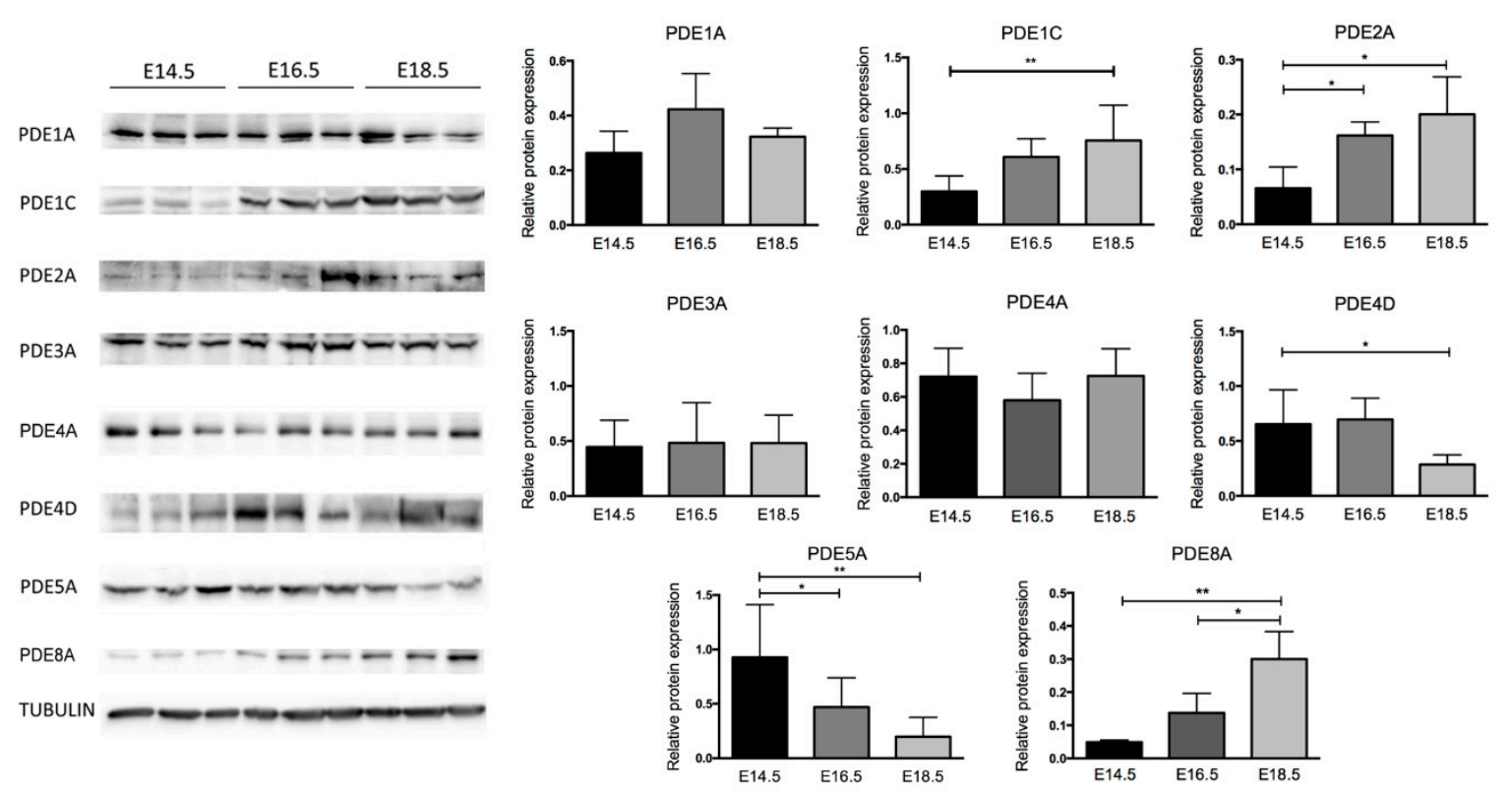

Figure 2. PDE protein expression during heart formation. Representative image of Western blot analysis and relative densitometric analysis of PDE1A, PDE1C, PDE2A, PDE3A, PDE4A, PDE4D, PDE5A and PDE8A proteins normalized with respect to Tubulin protein levels in E14.5, E16.5 and E18.5 mouse hearts. Data represent the mean \pm SD of at least three hearts for each embryonic stage. One-way ANOVA was used for statistical analysis, ${ }^{*} p<0.05,{ }^{* *} p<0.01$.

\subsection{Few PDEs Showed Enzymatic Activity Modulation at Embryonic and Fetal Life}

In the prenatal heart, the levels of cAMP and cGMP hydrolytic activities are stable during development (Figure 3).
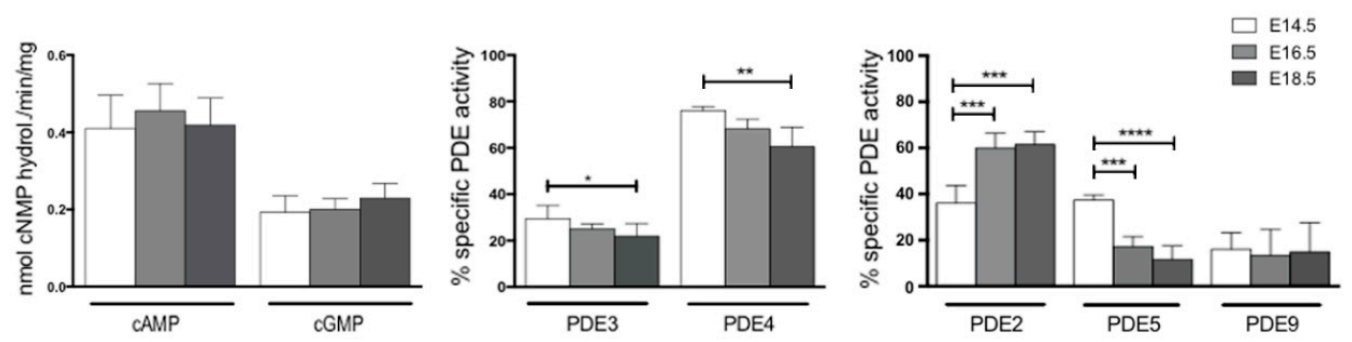

Figure 3. Total and specific PDE enzymatic activity during heart formation. Total cAMP and cGMP hydrolyzing activity from heart homogenates at E14.5 (white columns), E16.5 (light grey columns) and E18.5 (dark grey columns). PDE3- and PDE4-specific activities are reported as a percentage of total cAMP hydrolyzing activity evaluated after adding a fixed dose of the specific inhibitor milrinone and rolipram, respectively (see Materials and Methods). PDE2, PDE5 and PDE9 specific activities as a percentage of the total cGMP hydrolyzing activity evaluated after adding a fixed dose of the specific inhibitor BAY 60-7550, sildenafil and PF04449613, respectively (see Materials and Methods). Data represent the mean of three independent experiments $\pm \mathrm{SD}$. Each experiment was performed with a pool of 5 hearts per stage. One-way ANOVA was used for statistical analysis. ${ }^{*} p<0.05,{ }^{* *} p<0.01,{ }^{* * *} p<0.001,{ }^{* * * *} p<0.0001$.

Since specific inhibitors for many PDE isoforms are available, it was possible to measure the enzymatic activity of PDE2, 3, 4, 5 and 9 at different stages of heart development. cAMP-PDE activity assays were performed in cardiac homogenates in the presence of $10 \mu \mathrm{M}$ milrinone, the specific inhibitor of PDE3, and $30 \mu \mathrm{M}$ rolipram, the specific inhibitor of PDE4. The results obtained showed that almost 75\% of the total cAMP hydrolytic activity in the prenatal heart is due to PDE4 and the remaining 25\% to PDE3 activity (Figure 3).

PDE3 activity decreased with time, reaching statistical significance at E18.5, while PDE4 decreased more extensively compared to PDE3, showing a 15\% decrease from E14.5 to E16.5, whereas the reduction was 20\% from E14.5 to E18.5. 
cGMP-PDE activity assays were also performed in cardiac homogenates in the presence of $0.1 \mu \mathrm{M}$ BAY 60-7550, the specific inhibitor of PDE2; $0.1 \mu \mathrm{M}$ sildenafil, the specific inhibitor of PDE5; or $1 \mu \mathrm{M}$ PF04449613, the specific inhibitor of PDE9.

In the prenatal heart at E14.5, almost $80 \%$ of the total cGMP hydrolytic activity was divided at the same extent between PDE2 and PDE5, and the remaining 10\% was due to PDE9 (Figure 3). PDE2-dependent cGMP hydrolytic activity increased from $40 \%$ of the total activity at E14.5 to $60 \%$ at E16.5 and E18.5. In parallel, there was a significant decrease of PDE5-specific activity from the total $40 \%$ at E14.5 to less than $17 \%$ at E18.5. PDE9 activity was about $15 \%$ of total cGMP activity at every evaluated stage.

The PDE1 family comprises 3 genes for PDE1A, PDE1B and PDE1C activities, all able to hydrolyze both cAMP and cGMP [18]. Its hydrolytic activity was evaluated due to its unique property of being stimulated by $\mathrm{Ca}^{2+} / \mathrm{CaM}$ binding. The three isoforms displayed the same affinity for cGMP hydrolysis [22]; therefore, the total amount of PDE1stimulated activity was first assessed giving cGMP as substrate. As shown in Figure 4, cGMP hydrolyzing activity was stimulated two-fold in the presence of calcium and CaM, showing a constant level independent of the developmental stage.
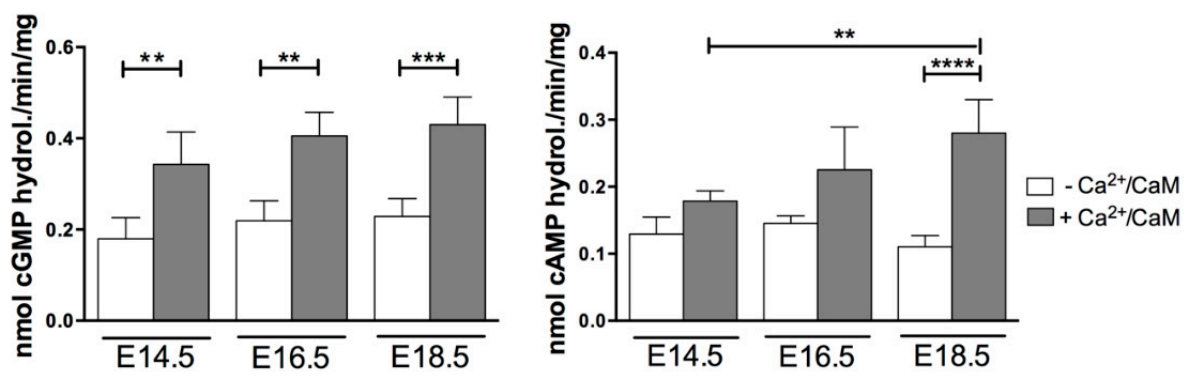

Figure 4. PDE1 enzymatic activity during the heart formation. Total PDE1 activity evaluated with cGMP as substrate in the presence of calcium and calmodulin. PDE1C activity assessed with $0.1 \mu \mathrm{M}$ cAMP as substrate in the presence of calcium and calmodulin. Data represent the mean of three independent experiments \pm SD. Each experiment was performed with a pool of 5 hearts per stage. Two-way ANOVA were used for statistical analysis. ${ }^{* *} p<0.01,{ }^{* * *} p<0.001,{ }^{* * * *} p<0.0001$.

Since there are no specific inhibitors to PDE1 isoforms but PDE1C has a higher affinity for cAMP with respect to the other two isoforms [23], its hydrolyzing activity was evaluated in the presence of $0.1 \mu \mathrm{M}$ cAMP (Figure 4). The results obtained showed a similar $\mathrm{Ca}^{2+} / \mathrm{CaM}$ stimulation in both E14.5 and E16.5 hearts and a significant stimulated increase at the E18.5 prenatal heart stage.

\section{Discussion}

The present study characterized the developmental pattern expression and enzymatic activity of PDEs at different stages of embryonic and fetal murine heart.

PDEs are evolutionary-conserved enzymes that, through the hydrolysis of cAMP and cGMP nucleotides, regulate the intracellular transduction signal of many hormones and growth factors involved in cardiac biology [7]. However, few data are available on the levels of cyclic nucleotides in the developing heart. Thakkar and Sperelakis assessed the cAMP and cGMP basal level content during chicken heart development [24]. Their data showed that the cAMP content was highest at early stages of heart development, decreasing with time, while the basal cGMP content was lowest early and increased at a later stage. It has been suggested that the adverse cAMP and cGMP basal content profile might be either due to a decrease of adenylyl and guanylyl cyclase activity or to an increase in PDE activity [24,25]. On the contrary, in isolated mouse cardiomyocytes with increasing age of development, it has been reported that cAMP content increased [26]. Here we report data showing that basal levels of cAMP and cGMP hydrolyzing activity did not change in the developing heart, ruling out the possibility that cyclic nucleotide basal level differences 
could be due to a modification of the heart cells ability to degrade them. In addition, these data indicated the existence of an equilibrium between the two cyclic nucleotides at least during heart developmental stages.

Previous data obtained by RT-PCR demonstrated that nine PDEs are expressed in the mouse developing heart [8]. These results were not only confirmed and extended by qRT-PCR, WB analyses and activity assays from this study, but we also showed that among the evaluated PDEs families, Pde1C, Pde2A, Pde4D, Pde5A and Pde8A displayed significant and never-described-before changes in expression in embryonic and fetal murine heart development. In particular, PDE1C, PDE2A and PDE8A activities showed a progressive significant increase while PDE4D and PDE5A showed a progressive decrease during heart formation. Moreover, we found that PDE2A and PDE5A accounts, with an increasingdecreasing adverse profile, respectively, for nearly $80 \%$ of the total cGMP hydrolyzing activities, while PDE3 and PDE4 accounts for more than $90 \%$ of the total cAMP hydrolyzing activity (Figure 3).

These data suggested the involvement of these activities during the construction of the main frame of the heart, while the other PDEs must have a role in specific modulatedadjusting functions to complete the transition from the embryonic to the final fetal organ.

In detail, we will describe the single-analyzed PDEs to elucidate, according to published data and to the results shown in this paper, the role played by each of them during the process of heart development.

PDE1 is a $\mathrm{Ca}^{2+} / \mathrm{CaM}$-stimulated phosphodiesterase family comprised of three genes for PDE1A, PDE1B and PDE1C activities, all able to hydrolyze both cAMP and cGMP [18].

The activity assay with cGMP as a substrate and $\mathrm{Ca}^{2+} / \mathrm{CaM}$, detecting together the three PDE1 stimulated activities, revealed a constant basal level throughout heart development. On the contrary, the $\mathrm{Ca}^{2+} / \mathrm{CaM}$-stimulated activity specifically associated with PDE1C at low concentration of cAMP [22] showed the same increase observed at mRNA and protein levels with the highest amount at E18.5, indicating that PDE1C might play a major role in the fetal heart rather than in the embryonic heart.

In fact, although PDE1C mutant mice do not present any cardiac alterations in physiological conditions, the genetic ablation of this isoform, expressed exclusively in cardiac myocytes, was associated with cardio-protection [11].

In line with the cell cycle exit of cardiomyocytes shortly after birth to terminal differentiation [27], the increased expression of PDE1C observed during heart development could be associated with PDE1C involvement in the control of cell proliferation as demonstrated in different studies. In particular, PDE1C plays a critical role in regulating the stability of growth factor receptors known to mediate important signaling pathways during heart formation [28].

The PDE2A gene gives rise to three isoforms localized in different cellular compartments, and they are all able to hydrolyze cAMP and cGMP at a similar rate [29]. PDE2A expression markedly increased at mRNA and protein levels at E18.5, accounting for $60 \%$ of the total cGMP hydrolyzing activity of fetal heart.

The importance of PDE2A in heart development is evident from its knockout at the embryo stage, which leads to severe cardiac alterations such as incomplete intraventricular septum, ventricular enlargement and hypertrabeculation before death takes place at E15.5 [9]. Moreover, PDE2A is the only PDE shown to be localized in mitochondria, where it is assembled in a multiprotein signaling complex with a specific mitochondrial adenylyl cyclase regulating the activity of the respiratory chain [30]. We cannot exclude that the increase in PDE2A during development could also be associated with the mitochondrial biogenic surge that occurs in cardiomyocytes at birth [31].

PDE5A, which specifically degrades CGMP, showed the highest protein level and hydrolyzing activity at E14.5 and the lowest levels at E18.5 stage.

PDE5A displays reduced levels in the adult heart under physiological conditions and increased levels in several pathological conditions; these differences with its levels during cardiac development suggested a correlation between its expression and hypoxic condition. 
In fact, at birth, the embryo undergoes a change from hypoxia to normoxia [31], while in the adult heart tissue, hypoxia seems to be one of the common features in cardiovascular disorders [32].

PDE4 is a large family of enzymes (PDE4A, 4B, 4C and 4D) of which A, B and D are expressed in the developing mouse heart, in cardiomyocytes and in murine cardiac tissue at comparable levels $[8,13,19]$. Despite the high amounts of PDE4 activity, the pharmacological inhibition and the genetic ablation of the PDE4A isoform in mice did not induce any cardiac alterations in animals at six months of age [33]. Conversely, the different phenotypes induced by the genetic ablation of PDE4D is probably due to their different subcellular localization and macromolecular complex interaction. Indeed, PDE4D knockout mice presents a progressive cardiomyopathy with a loss of $\beta$-adrenergic signaling in cardiac myocytes and heart failure after myocardial infarction [14,34].

In the developing mouse heart, the Pde4d mRNA expression is not modified over time, whereas, at the protein level, PDE4D showed a significant decreased expression at E18.5 (Figure 2). The decrease at the protein level is in agreement with the cAMP-hydrolytic activity decrease observed at the E18.5 stage while no changes were detected in the $4 \mathrm{~A}$ isoform at the stages examined.

It is well known that the cardiac autonomic nervous system modulates physiological cardiac functions such as heart rate and contraction force. The first signs of cardiac innervation during development are found in mouse dorsal mesocardium at E10.5 [35]. It has been reported that the heart rate of mice increases postnatally [36,37], mainly through the action of sympathetic system. One can speculate that the decreased expression of PDE4D in E18.5 heart could sustain sympathetic activity which in turn induce an increase in cAMP signaling through $\beta$-adrenergic receptor activation. In fact, detailed studies demonstrated the greatest role of PDE4D in the control of cAMP generated by $\beta$-adrenergic stimulation $[6,38]$.

Another cAMP-specific PDE showing a significant alteration of expression during cardiac development is PDE8A; both mRNA and protein levels significantly increased from E14.5 to the E18.5 stage of heart formation. Although the PDE4 family has a dominant role on the control of cAMP produced following $\beta$-adrenergic receptor stimulation, PDE8A is also involved in this pathway. Studies in isolated ventricular myocytes from Pde8a knockout hearts have demonstrated that this enzyme regulates $\mathrm{Ca}^{2+}$ signaling during $\beta$-adrenergic stimulation, suggesting that it could protect against cardiac arrhythmias [16]. However, further studies are required to fully understand the role of PDE8A in heart.

In conclusion, this study showed that there is a modulation of PDEs' expression at different stages of heart formation which tends to keep constant the total hydrolyzing activity of the heart. The expression of multiple PDE isoenzymes degrading cAMP/cGMP over a wide range of concentrations, and whose activity is dynamic due to PDE regulation by numerous intracellular signals, contributes to the very complex scenario in the regulation of cyclic nucleotide pathways during cardiac development. An additional and important property of the PDE system is its ability to operate in discrete subcellular compartments through macromolecular complexes organized by scaffold proteins. This organization creates high concentrations of specific PDEs which regulate distinct pools of cyclic nucleotides and, in turn, specific cellular processes [39].

Further studies will be necessary to better understand the localization and subcellular functions of different PDEs at different stages of heart formation and to verify if dysregulation of these patterns of expression could be involved in cardiac malformations during the intrauterine life.

\section{Materials and Methods}

\subsection{Mouse Husbandry and Embryos Collection}

All the animal procedures conformed to the Directive 2010/63/EU of the European Parliament on the protection of animals used for scientific purposes, and they were conducted with the approval of the Sapienza University's Animal Use for Research Ethic 
Committee and by the Italian Ministry of Health with protocol number DGSAF 24675-A (2013) and 919/2020-PR. Male and female C57BL/6 wild type from eight to twelve weeks of age were mated to generate embryos and fetus mice. The day of vaginal plug was considered as embryonic day 0.5 (E0.5). The animals had access to food and drinking water ad libitum and maintained in a light-dark cyclic of $12-12 \mathrm{~h}$ and temperature at $20-25^{\circ} \mathrm{C}$. At $14.5,16.5$ and 18.5 days of heart formation, embryos and fetuses were dissected from the yolk sac after cervical dislocation of pregnant mouse. The embryonic and fetal hearts were collected in phosphate buffer saline and stored at $-80^{\circ} \mathrm{C}$ for future analysis.

\section{2. $q R T-P C R$}

Total RNA was isolated from five embryonic heart tissues using total RNA isolation Microprep Kit-BioRad following the manufacturer's instructions. The RNA was treated with DNase I Zymol and, after, was reverse-transcribed to synthesize cDNA through Maxima $\mathrm{H}$ minus reverse transcriptase (Thermo Fischer Scientific, Waltham, MA, USA). For qRT-PCR, samples were amplified in the reaction mixture with PowerUp SYBR green Master Mix (Thermo Fisher Scientific) and specific primers for phosphodiesterases in Thermo Fisher Scientific 7500 Real-Time PCR instrument. For quantification analysis, the comparative threshold cycle $(\mathrm{Ct})$ method was used. The $\mathrm{Ct}$ values of each gene were normalized to the $\mathrm{Ct}$ value of Gapdh in the same RNA sample. The gene expression levels were evaluated by the fold change using the equation $2^{-\mathrm{ddCt}}$. The primers used in the present study are listed in the Table 2.

Table 2. qRT-PCR primers.

\begin{tabular}{|c|c|c|}
\hline Gene & Forward Primer & Reverse Primer \\
\hline Pde1a & 5'AGGTATCATGCACTGGCTCA $3^{\prime}$ & 5'GAGCGGTCGTTGTACAGAAT 3' \\
\hline Pde1c & 5'ATGGGGATGATGCTTAGGAG 3' & 5' CAATGCTTCGATTACAGCCG 3' \\
\hline$P d e 2 a$ & $5^{\prime}$ ACCGAAAGATCCTGCAACTG $3^{\prime}$ & $5^{\prime}$ TTCTCCCAGCACTTTGTCTC $3^{\prime}$ \\
\hline$P d e 3 a$ & $5^{\prime}$ AGAATCCATGCCACCGATGT $3^{\prime}$ & $5^{\prime}$ CCCATGTGTCCGTGTGTAAA $3^{\prime}$ \\
\hline$P d e 4 a$ & $5^{\prime}$ TGCTGCAAGAGAACTGC $3^{\prime}$ & 5' AGGGTCATGTGCTTGGACAT 3' \\
\hline Pde4d & 5'GCCTCTGACTGTTATCATGCAC3' & 5' GCAGCATGGATGTTGTTGTG 3' \\
\hline Pde5a & $5^{\prime}$ ATCCATGGACTCATCTCTGC $3^{\prime}$ & $5^{\prime}$ GCTTCCTCCAATGTTGAACC $3^{\prime}$ \\
\hline Pde8a & $5^{\prime}$ TCAGAGTGTGCAATGGCAAC $3^{\prime}$ & 5'GTCCATCGAATGTTTCCTCC $3^{\prime}$ \\
\hline Pde9 & $5^{\prime}$ CTACGAGGAGCTGAAGCAGC $3^{\prime}$ & 5' AGTTTGGAGGAGAATGGCCT 3' \\
\hline Gapdh & $5^{\prime}$ GTGAAGGTCGGTGTGAACG $3^{\prime}$ & $5^{\prime}$ ATTTGATGTTAGTGGGGTCTCG3' \\
\hline
\end{tabular}

\subsection{Western Blot}

To evaluate the protein expression of PDEs during cardiac development, a Western blotting analysis was performed. Protein samples were extracted from embryonic heart and lysed in RIPA lysis buffer $1 \times$ (Merck Millipore Darmstadt, Germany) supplemented with protease and phosphatase inhibitors. The protein concentration was measured by Bradford method. An amount of $30 \mu \mathrm{g}$ of protein was electrophoresed in 8-10\% SDS-page gels and transferred onto nitrocellulose membrane. The membrane was immersed in $5 \%$ $v / v$ blocking milk (TBST $+5 \%$ non-fat milk) for $1 \mathrm{~h}$ at room temperature and incubated in primary antibodies (1:500 $v / v$ in TBST $+5 \% w / v$ BSA (bovine serum albumin) buffer) for phosphodiesterase detection (PDE1A FabGennix \#PDE1A-101AP; PDE1C FabGennix \#PD1C301AP; PDE2A Abcam \#ab140650; PDE3A Santa Cruz \#sc-20792; PDE4A Proteintech \#16226-1-AP; PDE4D Invitrogen \#PA5-79795; PDE5A Santa Cruz \#32884; PDE8A Sigma Aldrich \#HPA007722) overnight at $4{ }^{\circ} \mathrm{C}$. After, the membranes were washed in TBST and incubated in appropriated horseradish peroxidase (HRP)-conjugated secondary antibodies $(1: 10,000 v / v$ in TBST) for $1 \mathrm{~h}$ at room temperature. Chemiluminescent images of immunodetected bands were recorded with the Syngene G-box system (Syngene Bioimaging, 
India) and immunoblot intensities were quantitatively analyzed using ImageJ Software (NIH, Bethesda, MD, USA).

\subsection{PDEs Activity Assay}

Embryonic hearts were homogenized using a glass homogenizer $\left(15\right.$ strokes, $\left.4{ }^{\circ} \mathrm{C}\right)$ in $20 \mathrm{mM}$ Tris- $\mathrm{HCl}$ buffer $\mathrm{pH} 7.2$ containing $0.2 \mathrm{mM}$ EGTA, $5 \mathrm{mM} \beta$-mercaptoethanol, $2 \% v / v$ antiprotease cocktail (Sigma-Aldrich, St. Louis, MO, USA), $1 \mathrm{mM} \mathrm{PMSF,} 5 \mathrm{mM} \mathrm{MgCl} 2,0.2 \%$ $v / v$ Triton X-100. The homogenates were centrifuged at $14,000 \times g$ for 30 min at $4{ }^{\circ} \mathrm{C}$.

PDE activity was measured on the supernatant with the method described by Thompson and Appleman [40] in $60 \mathrm{mM}$ Hepes pH 7.2, $0.1 \mathrm{mM}$ EGTA, $5 \mathrm{mM} \mathrm{MgCl}$, $0.5 \mathrm{mg} / \mathrm{mL}$ bovine serum albumin (BSA) and $30 \mathrm{mg} / \mathrm{mL}$ soybean trypsin inhibitor in a final volume of $0.15 \mathrm{~mL}$. Ca ${ }^{2+}$-calmodulin stimulation was determined in the presence of $1 \mathrm{mM} \mathrm{CaCl}_{2}$ and $3 \mu \mathrm{g} / \mathrm{mL}$ calmodulin. The reaction was started by adding tritiated substrates at a final concentration of $1 \mu \mathrm{M}\left[{ }^{3} \mathrm{H}\right]$ cAMP or $\left[{ }^{3} \mathrm{H}\right]$ cGMP, and $0.1 \mu \mathrm{M}\left[{ }^{3} \mathrm{H}\right]$ cAMP for PDE1C detection. The reaction was stopped by adding $50 \mu \mathrm{L}$ of $0.1 \mathrm{~N} \mathrm{HCl}$ and then neutralized with $50 \mu \mathrm{L}$ of $0.1 \mathrm{~N} \mathrm{NaOH}$ in $0.1 \mathrm{M}$ Tris- $\mathrm{HCl} \mathrm{pH}$ 8.0. Subsequently, $25 \mu \mathrm{L}$ of $2 \mathrm{mg} / \mathrm{mL}$ of $5^{\prime}$-nucleotidase (snake venom from Crotalus atrox; Sigma-Aldrich) in $0.1 \mathrm{M}$ Tris- $\mathrm{HCl} \mathrm{pH}$ 8.0 were added. Samples were gently mixed and incubated at $30^{\circ} \mathrm{C}$ for $30 \mathrm{~min}$ to allow complete conversion of $5^{\prime}$-nucleotide to its corresponding nucleoside. Unhydrolyzed cyclic nucleotide and the corresponding nucleoside were separated by DEAE-Sephadex A-25 columns. The eluate was mixed with ULTIMA GOLD scintillation liquid (PerkinElmer) and counted on a Tri-Carb 2100TR Liquid Scintillation Counter (2000CA; Packard Instruments, Meriden, CT, USA).

To evaluate the enzymatic specific activity of each PDEs, the specific inhibitors were added to the reaction mix at the following concentration: $10 \mu \mathrm{M}$ milrinone (PDE3 inhibitor), $0.1 \mu \mathrm{M}$ BAY 60-7550 (PDE2 inhibitor), $30 \mu \mathrm{M}$ rolipram (PDE4 inhibitor), $0.1 \mu \mathrm{M}$ sildenafil (PDE5 inhibitor) and $1 \mu \mathrm{M}$ PF04449613 (PDE9 inhibitor). The percentage of each PDE was calculated comparing the difference between the total PDE activity and the residual PDE activity assayed in the presence of the specific inhibitor with respect to the total PDE activity fixed as $100 \%$.

\subsection{Statistics Analysis}

The data obtained were statistically analyzed using the GraphPad Prism 5.0 (GraphPad software, San Diego, CA, USA). Comparison among groups was performed with the oneway ANOVA or two-way ANOVA and multiple comparisons by Tukey test. A $p$ value of $<0.05$ was considered statistically significant; all data were presented as mean $\pm \mathrm{SD}$.

Author Contributions: F.N. conceived the study and planned the experiments. T.M.d.C.S.C., S.C., M.G., performed the experiments and analyzed the data; F.N. supervised the experiments; T.M.d.C.S.C., S.C., M.G., F.N. drafted the manuscript; F.N., A.L., A.M.I. supervised the project, T.M.d.C.S.C., A.L., A.M.I., F.N. funded the project. All authors have read and agreed to the published version of the manuscript.

Funding: This work was supported by research funding from Sapienza University Progetti per Avvio alla Ricerca-Tipo 1 protocollo AR11916B84EC05AF to TMCSC and Progetto di Ateneo 2017 to F.N.; Saving Tiny Hearts Society-000315_19APE NARO to F.N.

Institutional Review Board Statement: The study was conducted according to the Directive 2010/63/ EU of the European Parliament on the protection of animals used for scientific purposes and with the approval of the Sapienza University's Animal Use for Research Ethic Committee and by the Italian Ministry of Health (protocol number DGSAF 24675-A 2013 and 919/2020-PR).

Informed Consent Statement: Not applicable.

Data Availability Statement: Not applicable. 
Acknowledgments: We are grateful to Federica Barbagallo and Federica Campolo for technical assistance in Western blot analysis and for reagent sharing (Sapienza University of Rome). We acknowledge the precious suggestions and critical comments of Michele Saliola (Sapienza University of Rome).

Conflicts of Interest: The authors declare no conflict of interest. The funders had no role in the design of the study; in the collection, analyses, or interpretation of data; in the writing of the manuscript; or in the decision to publish the results.

$\begin{array}{ll}\text { Abbreviations } \\ \text { E. } & \text { Embryonic day } \\ \text { cAMP } & \text { Cyclic adenosine monophosphate } \\ \text { cGMP } & \text { Cyclic guanosine monophosphate } \\ \text { AC } & \text { Adenylyl cyclase } \\ \text { NO } & \text { Nitric oxide } \\ \text { PDE } & \text { Phosphodiesterase } \\ \mathrm{Ca}^{2+} & \text { Calcium } \\ \text { CaM } & \text { Calmodulin } \\ \text { TAC } & \text { Transverse aortic constriction }\end{array}$

\section{References}

1. Boer, A.B.; Berg, G.V.D.; Boer, P.A.J.; Moorman, A.F.M.; Ruijter, J.M. Growth of the developing mouse heart: An interactive qualitative and quantitative 3D atlas. Develop. Biol. 2012, 368, 203-213. [CrossRef] [PubMed]

2. Savolainen, S.M.; Foley, J.F.; Elmore, S.A. Histology atlas of the developing mouse heart with emphasis on E11.5 to E18.5. Toxicol. Pathol. 2009, 37, 395-414. [CrossRef] [PubMed]

3. Roche, P.; Czubryt, M.P.; Wigle, J.T. Molecular mechanisms of cardiac development- (Cardiac adaptations- chapter 2). In Cardiac Adaptations; Advances in Biochemistry in Health and Disease; Ostadal, B., Dhalla, N., Eds.; Springer: New York, NY, USA, 2012; Volume 4.

4. Maurice, D.H.; Ke, H.; Ahmad, F.; Wang, J.; Chung, J.; Manganiello, V.C. Advances targeting cyclic nucleotide phosphodiesterases. Nat. Rev. Drug. Discov. 2014, 13, 290-314. [CrossRef]

5. Knight, W.E.; Yan, C. Cardiac cyclic nucleotide phosphodiesterases: Function, regulation and therapeutic prospects. Horm. Metab. Res. 2012, 44, 766-775. [CrossRef]

6. Zaccolo, M.; Movsesian, M.A. cAMP and cGMP signaling cross-talk: Role of phosphodiesterases and implications for cardiac pathophysiology. Circ. Res. 2007, 100, 1569-1578. [CrossRef] [PubMed]

7. Maurice, D.H.; Palmer, D.; Tilley, D.G.; Dunkerley, H.A.; Netherton, S.J.; Raymond, D.R.; Elbatarny, H.S.; Jimmo, S.L. Cyclic nucleotide phosphodiesterase activity, expression and targeting in cells of the cardiovascular systems. Mol. Pharmacol. 2003, 64, 533-546. [CrossRef] [PubMed]

8. Isidori, A.M.; Cornacchione, M.; Barbagallo, F.; Grazia, A.; Barrios, F.; Fassina, L.; Monaco, L.; Giannetta, E.; Gianfrilli, D.; Garofalo, S.; et al. Inhibition of type 5 phosphodiesterase counteracts $\beta 2$-adrenergic signaling in beating cardiomyocytes. Circ. Res. 2015, 106, 408-420.

9. Assenza, M.R.; Barbagallo, F.; Barios, F.; Cornacchione, M.; Campolo, F.; Vivarelli, E.; Gianfrilli, D.; Auletta, L.; Soricelli, A.; Isidori, A.M.; et al. Critical role of phosphodiesterase 2A in mouse congenital heart defects. Cardiovasc. Res. 2018, 114, 830-845. [CrossRef]

10. Wang, X.; Yamada, S.; LaRiviere, W.B.; Ye, H.; Bakeberg, J.L.; Irazabal, M.V.; Chebib, F.T.; Van Deursen, J.; Harris, P.C.; Sussman, C.R.; et al. Generation and phenotypic characterization of PDE1a mutant mice. PLoS ONE 2017, 12, e0181087. [CrossRef] [PubMed]

11. Knight, W.E.; Chen, S.; Zhang, Y.; Oikawa, M.; Wu, M.; Zhou, Q.; Miller, C.L.; Cai, Y.; Mickelsen, D.M.; Moravec, C.; et al. PDE1C deficiency antagonizes pathological cardiac remodeling and dysfunction. Proc. Natl. Acad. Sci. USA 2016, 113, E7116-E7125. [CrossRef]

12. Oikawa, M.; Wu, M.; Lim, S.; Knight, W.E.; Miller, C.L.; Cai, Y.; Lu, Y.; Blaxall, B.C.; Takeishi, Y.; Abe, J.; et al. Cyclic nucleotide phosphodiesterase 3A1 protects the heart against ischemia reperfusion injury. J. Mol. Cell. Cardiol. 2014, 64, 11-19. [CrossRef] [PubMed]

13. Leroy, J.; Richter, W.; Mika, D.; Castro, L.R.V.; Abi-Gerges, A.; Xie, M.; Scheitrum, C.; Lefebvre, F.; Schittl, J.; Mateo, P.; et al. Phosphodiesterase 4B in the cardiac L-type $\mathrm{Ca}^{2+}$ channel complex regulates $\mathrm{Ca}^{2+}$ current and protects against ventricular arrhythmias in mice. J. Clin. Investig. 2011, 121, 2651-2661. [CrossRef] [PubMed]

14. Lehnart, S.E.; Wehrens, X.H.T.; Reiken, S.; Warrier, S.; Belevych, A.E.; Harvey, R.D.; Richter, W.; Jin, S.-L.C.; Conti, M.; Marks, A.R. Phosphodiesterase $4 \mathrm{~d}$ deficiency in the Ryanodine-Receptor complex promotes heart failure and arrhythmias. Cell 2005, 123, 25-35. [CrossRef] [PubMed] 
15. Pokreisz, P.; Vandenwijngaert, S.; Bito, V.; Van den Bergh, A.; Lenaerts, I.; Busch, C.; Marsboom, G.; Gheysens, O.; Vermeersch, P.; Biesmans, L.; et al. Ventricular phosphodiesterase- 5 expression is increased in patients with advanced heart failure and contributes to adverse ventricular remodeling after myocardial infarction in mice. Circulation 2009, 119, 408-416. [CrossRef] [PubMed]

16. Patrucco, E.; Albergine, M.S.; Santana, L.F.; Beavo, J.A. Phosphodiesterase 8A (PDE8A) regulates excitation-contraction coupling in ventricular myocytes. J. Mol. Cell. Cardiol. 2010, 49, 330-333. [CrossRef] [PubMed]

17. Lee, D.I.; Zhu, G.; Sasaki, T.; Cho, G.S.; Hamdani, N.; Holewinski, R.; Jo, S.-H.; Danner, T.; Zhang, M.; Rainer, P.P.; et al. Phosphodiesterase 9A controls nitric-oxide-independent cGMP and hypertrophic heart disease. Nature 2015, 519, 472-476. [CrossRef] [PubMed]

18. Chen, S.; Knight, W.E.; Yan, C. Roles of PDE1 in Pathological cardiac remodeling and dysfunction. J. Cardiovasc. Dev. Dis. 2018, 5, 22. [CrossRef]

19. Abi-Gerges, A.; Richter, W.; Lefebvre, F.; Mateo, P.; Varin, A.; Heymes, C.; Samuel, J.-L.; Lugnier, C.; Conti, M.; Fischmeister, R.; et al. Decreased Expression and Activity of cAMP Phosphodiesterases in Cardiac Hypertrophy and Its Impact on $\beta$-Adrenergic cAMP Signals. Circ. Res. 2009, 105, 784-792. [CrossRef]

20. Catalano, S.; Campana, A.; Giordano, C.; Győrffy, B.; Tarallo, R.; Rinaldi, A.; Bruno, G.; Ferraro, A.; Romeo, F.; Lanzino, M.; et al. Expression and function of phosphodiesterase type 5 in human breast cancer cell lines and tissues: Implications for targeted therapy. Clin. Cancer Res. 2015, 22, 2271-2282. [CrossRef] [PubMed]

21. Dorner-Ciossek, C.; Kroker, K.S.; Rosenbrock, H. Role of PDE9 in cognition. Adv. Neurobiol. 2017, 17, 231-254.

22. Bender, A.T.; Beavo, J.A. Cyclic nucleotide phosphodiesterases: Molecular regulation to clinical use. Pharmacol. Rev. 2006, 58, 488-520. [CrossRef]

23. Omori, K.; Kotera, J. Overview of PDEs and their regulation. Circ. Res. 2007, 100, 309-327. [CrossRef]

24. Thakkar, J.K.; Sperelakis, N. Changes in cyclic nucleotide levels during embryonic development in chick hearts. J. Dev. Physiol. 1987, 9, 497-505. [PubMed]

25. Hosey, M.M.; Green, R.D. Effects of isoproterenol on cyclic AMP and cyclic AMP dependent protein kinase in developing chick myocardium. Biochim. Biophys. Acta 1977, 500, 152-161. [CrossRef]

26. Feridooni, T.; Hotchkiss, A.; Baguma-Nibasheka, M.; Zhang, F.; Allen, B.; Chinni, S.; Pasumarthi, K.B.S. Effects of $\beta$-adrenergic receptor drugs on embryonic ventricular cell proliferation and differentiation and their impact on donor cell transplantation. Am. J. Physiol. Heart Circ. Physiol. 2017, 312, H919-H931. [CrossRef]

27. Galdos, F.X.; Guo, Y.; Paige, S.L.; VanDusen, N.J.; Wu, S.M.; Pu, W.T. Cardiac Regeneration: Lessons from Development. Circ. Res. 2017, 120, 941-959. [CrossRef] [PubMed]

28. Cai, Y.; Nagel, D.J.; Zhou, Q.; Cygnar, K.D.; Zhao, H.; Li, F.; Pi, X.; Knight, P.A.; Yan, C. Role of cAMP-phosphodiesterase $1 \mathrm{C}$ signaling in regulating growth factor receptor stability, vascular smooth muscle cell growth, migration, and neointimal hyperplasia. Circ. Res. 2015, 116, 1120-1132. [CrossRef]

29. Pavlaki, N.; Nikolaev, V.O. Imaging of PDE2 and PDE3 mediated cGMP-to cAMP cross-talk in cardiomyocytes. J. Cardiovasc. Dev. Dis. 2018, 5, 4. [CrossRef] [PubMed]

30. Acin-Perez, R.; Russwurm, M.; Günnewig, K.; Gertz, M.; Zoidl, G.; Ramos, L.; Buck, J.; Levin, L.R.; Rassow, J.; Manfredi, G.; et al. A phosphodiesterase 2A isoform localized to mitochondria regulates respiration. J. Biol. Chem. 2011, 286, 30423-30432. [CrossRef] [PubMed]

31. Zhao, Q.; Sun, Q.; Zhou, L.; Liu, K.; Jiao, K. Complex Regulation of Mitochondrial Function During Cardiac Development. J. Am. Heart Assoc. 2019, 8, e012731. [CrossRef]

32. Abe, H.; Semba, H.; Takeda, N. The Roles of Hypoxia Signaling in the Pathogenesis of Cardiovascular Diseases. J. Atheroscler. Thromb. 2017, 24, 884-894. [CrossRef]

33. Conti, M. Subcellular targeting of PDE4 in cardiac myocytes and generation of signaling compartments. In Microdomains in the Cardiovascular System; Cardiac and Vascular Biology; Nikolaev, V., Zaccolo, M., Eds.; Springer: Berlin/Heidelberg, Germany, 2017.

34. Xiang, Y.; Naro, F.; Zoudilova, M.; Jin, S.L.C.; Conti, M.; Kobilka, B. Phosphodiesterase 4D is required for B2 adrenoreceptor subtype-specific signaling in cardiac myocytes. Proc. Natl. Acad. Sci. USA 2005, 102, 909-914. [CrossRef]

35. Hildreth, V.; Webb, S.; Bradshaw, L.; Brown, N.A.; Anderson, R.H.; Henderson, D.J. Cells migrating from the neural crest contribute to the innervation of the venous pole of the heart. J. Anat. 2008, 212, 1-11. [CrossRef] [PubMed]

36. Adachi, T.; Shibata, S.; Okamoto, Y.; Sato, S.; Fujisawa, S.; Ohba, T.; Ono, K. The mechanism of increased postnatal heart rate and sinoatrial node pacemaker activity in mice. J. Physiol. Sci. 2013, 63, 133-146. [CrossRef] [PubMed]

37. Sato, S. Quantitative evaluation of ontogenetic change in heart rate and its autonomic regulation in newborn mice with the use of a noninvasive piezoelectric sensor. Am. J. Physiol. Heart Circ. Physiol. 2008, 294, H1708-H1715. [CrossRef]

38. Bolger, G.B. RACK1 and $\beta$-arrestin2 attenuate dimerization of PDE4 cAMP phosphodiesterase PDE4D5. Cell Signal. 2016, 28, 706-712. [CrossRef]

39. Conti, M.; Mika, D.; Richter, W. Cyclic AMP compartments and signaling specificity: Role of cyclic nucleotide phosphodiesterases. J. Gen. Physiol. 2014, 143, 29-38. [CrossRef]

40. Thompson, W.J.; Appleman, M.M. Multiple cyclic nucleotide phosphodiesterase activities from rat brain. Biochemistry 1971, 10, 311-316. [PubMed] 